\title{
Maintaining standing stones benefits biodiversity in lowland heathland
}

\author{
Emma Shepheard - Walwyn and Shonil A. Bhagwat
}

\begin{abstract}
The exploitation of natural resources by people generally has detrimental effects on nature but in some cases anthropogenic activities can result in changes to the natural environment that produce new habitats and increase biodiversity. Understanding and supporting such cultural aspects of land use is an important part of effective conservation strategies. The UK has a range of cultural landscapes that contribute to the landscape matrix and are often important for biodiversity. However, little research has been conducted on the relationship between various types of cultural landscapes or their effects on biodiversity. We examined the interaction between semi-natural sacred sites and lowland heathland in Cornwall, and the contribution these sites make to the overall biodiversity within the habitat. We found that semi-natural sacred sites had significantly higher levels of biodiversity compared to surrounding heathland; the existence and use of the sites created new and important habitats for rare and threatened heathland species; and the spiritual and cultural use of the sites aids the management of heathland. Promoting the use of semi-natural sacred sites could therefore contribute to biodiversity conservation. Furthermore, the cultural and spiritual importance of such sites potentially increases the availability of volunteer resources for their management. We highlight the importance of an integrated management approach for achieving effective biodiversity conservation in areas containing multiple types of cultural landscapes.
\end{abstract}

Keywords Biodiversity, Biodiversity Action Plan habitats, Cornwall, cultural landscape, heathland, semi-natural sacred sites, standing stones, UK

Supplementary material for this article is available at https://doi.org/10.1017/Soo30605317001442

\section{Introduction}

he detrimental effects of human activities on nature
have prompted many conservation practitioners to
attempt to keep nature separate from people. However, in

Emma Shepheard-Walwyn (Corresponding author) The White House Cottage, Stockland, Devon, EX14 9DS, UK. E-mail eshepw@hotmail.com

Shonil A. Bhagwat Department of Geography, Open Space Research Centre, The Open University, UK

Received 30 January 2017. Revision requested 19 May 2017

Accepted 18 September 2017. First published online 22 February 2018. some cases anthropogenic influence can produce new habitats and diversity within the landscape, resulting in a more biodiverse environment (Jones, 2003; Bhagwat et al., 2008; Anthwal et al., 2010). Many ecosystems have been altered historically by human activities, and areas previously considered to be pristine have been found to have been sites of historical large-scale anthropogenic changes (Moran, 2006). Understanding and supporting the cultural aspects of land use is therefore, in some cases, an important part of an effective conservation strategy.

Anthropogenic activities in the natural environment result in cultural landscapes (Jones, 2003; Agnoletti, 2004), which can provide information about the way in which nature responds to human influences, and how anthropogenic use can help to promote biodiversity (Agnoletti, 2004; Willis et al., 2004; Anthwal et al., 2010). Globally there are examples of both positive and negative influences of people's actions on the natural environment; cultural landscapes, from single prayer trees to the extensive agricultural landscapes of Europe, are a product of such actions (Jones, 2003; Moran, 2006; Bhagwat et al., 2008). Many cultural landscapes help to contribute towards the heterogeneity of the landscape matrix and provide unique opportunities for biodiversity conservation (Agnoletti, 2004; Bhagwat et al., 2008; Dudley et al., 2010).

There have been studies of the contributions of various types of cultural landscapes in the landscape matrix (Bhagwat et al., 2008), and the importance of the variation of habitats within particular cultural landscapes (Kirby, 1992; Key, 2000; Price, 2003). However, there has been less focus on habitat heterogeneity within cultural landscapes, and no previous research has investigated directly the effects of sacred sites on biodiversity in lowland heathland.

There is a variety of cultural landscapes in the UK, including agricultural landscapes, heathland and moorland, managed forests, urban green spaces, and sacred sites. Many sacred sites in the UK can be categorized as seminatural sacred sites because of their presence in otherwise highly anthropogenic landscapes. Here we examine seminatural sacred sites in lowland heathland, and the contribution these sites make to biodiversity within the heathland habitat. We address five questions: (1) What is the extent and spatial distribution of known semi-natural sacred sites within lowland heathland in Cornwall? (2) What are the differences in community structure and composition between these sites and the surrounding heathland? (3) How does the use of semi-natural sacred sites affect the structure and composition of surrounding habitat, and what impact does this 
have on biodiversity? (4) What are the differences in habitat diversity between semi-natural sacred sites and heathland? (5) What contribution do semi-natural sacred sites make to the biodiversity of the heathland?

\section{Study area}

This study was conducted in the region of Penwith, West Cornwall, in south-west England (Fig. 1). The west of Penwith is an Environmentally Sensitive Area (Natural England, 2008).

\section{Lowland heathland}

Lowland heathland is an anthropogenic landscape that occurs up to $300 \mathrm{~m}$ altitude. Most heathland requires active management to prevent trees becoming dominant in the landscape (Price, 2003; D. Allen, 2009, pers. comm.). Twenty percent of all remaining lowland heathland is in the UK, and the majority of this is in the south of England (Price, 2003). Lowland heathlands are vital to many rare species, such as the smooth snake Coronella austriaca, the nightjar Caprimulgus europaeus and the ladybird spider Eresus sandaliatus (Forestry Commission, 2017), and therefore the management of these lands is vital to the protection of much of the UK's biodiversity (Kirby, 1992; Key, 2000; Price, 2003). An important aspect of heathlands is the variation of structures and habitats within them (Kirby, 1992; Key, 2000; Price, 2003), including areas dominated by gorse Ulex and heather Calluna, areas of open grass and bare soil, and wet areas including boggy patches or open water (Hantsweb, 2009). In addition, footpaths, bare ground, rocky structures, artificial features and ruins can all provide heterogeneity within the landscape matrix, which is essential for biodiversity (Kirby, 1992; Key, 2000; Price, 2003).

\section{Neolithic stone monuments}

There are many ancient sites in the Penwith region that hold important cultural and spiritual significance, including a large number of Neolithic stone monuments (Media, 2009). This research focuses on Pagan standing stones and burial sites that date back to the Neolithic and Early Bronze Age, c. 3,300-1,500 BC (Burl, 2000; A2M, 2009; Historic Environment Service, 2009; UNESCO, 2016). Although these monuments are not as widely used for spiritual purposes as they once were, they are still considered to be sacred by some people (Taylor \& Kaplan, 2008; Pratt, 2015), and 'West Penwith is home to many followers of contemporary paganism, for whom the prehistoric sites hold particular spiritual resonance' (Pratt, 2015). The monuments are also important for their historical and cultural significance, and are categorized as semi-natural sacred sites. They harbour natural habitats that have been altered through extensive human influence over time (Bhagwat \& Rutte, 2006; Anthwal et al., 2010; Shepheard-Walwyn, 2014), and they have been found to support biodiversity that differs from that of surrounding habitats (Bhagwat \& Rutte, 2006; Dudley et al., 2010). We focus on five types of stone monuments (standing stones, stone circles, cairns, quoits and tumuli) regarded as sacred by Pagan worshippers, and consider 32 sites: 16 semi-natural sacred sites (Table 1) and 16 (paired) non-sacred sites within lowland heathland.

\section{The co-existence of Neolithic monuments with heathland}

Lowland heathland in Western Europe is a highly managed habitat, and without management it would return to forest (Price, 2003). In Britain, Neolithic monuments and stone structures are embedded within this habitat. Archaeological evidence suggests that Neolithic cultures practised farming and pastoralism, which are associated with widespread clearing of forest and expansion of farmland (Heil \& Aerts, 1993; Gaillard et al., 2009). The sacredness of the stone structures therefore lies in the stones rather than in the land per se, so management of heathland and maintenance of sacred stone structures would have coexisted in Neolithic times.

\section{Methods}

We used a combination of fieldwork and a geographical information system to map semi-natural sacred sites in lowland heathland and analyse their distribution in the landscape, and the differences in vegetation, habitat and biodiversity between paired sacred and non-sacred sites.

\section{Selection of study sites}

To select the study sites we conducted analysis using ArcGIS v. 9, ArcMap v. 9.3 and ArcCatalog v. 9.3 (ESRI, Redlands, USA). All maps were produced using the Transverse Mercator projection, with central meridian at -2.00 , and the coordinate system GCS_OSGB_1963 unless otherwise stated. The megalithic map of the UK (Burnham, 2001) was used to identify ancient, sacred and cultural sites across Cornwall. Terrestrial sites noted in the literature as having spiritual association were shortlisted, and a database of site name, map coordinates and type was compiled to facilitate mapping of these sites. Following Oldfield et al. (2004) and Xiang (1993), the sacred sites located within important habitat types (according to the UK Biodiversity Action Plan; JNCC, 2009) in Cornwall were located using a combination of select-by-location and cookie-cutter functions. Using the select-by-location tool, features can be selected based on 


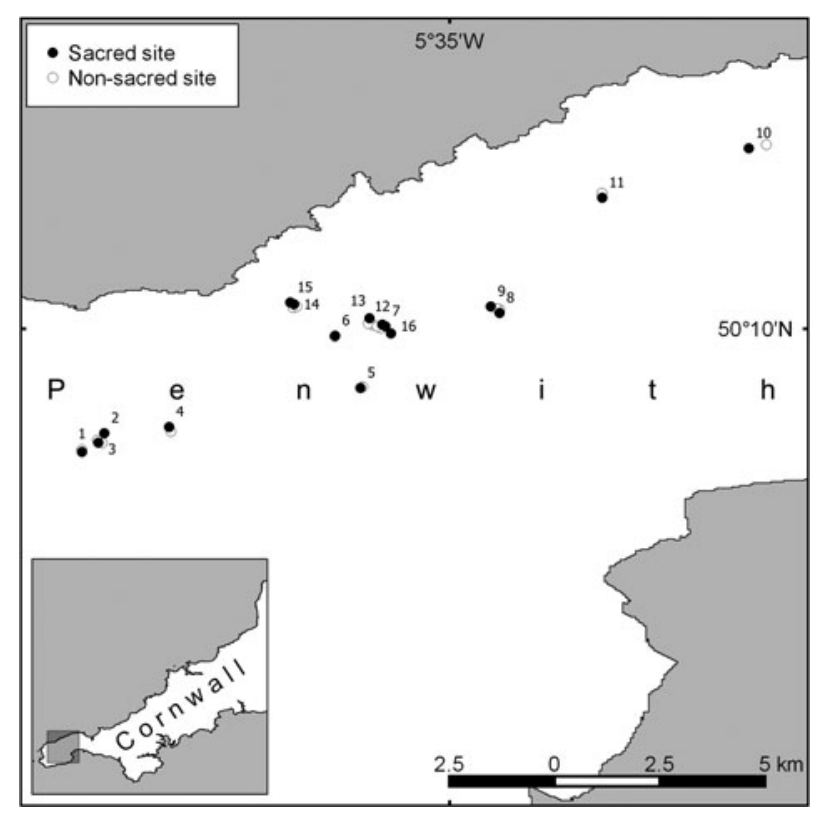

FIG. 1 The locations of the study sites, 16 semi-natural sacred sites (Table 1) and their paired non-sacred sites, used to investigate differences in biodiversity and habitat between sacred and non-sacred sites in Penwith, Cornwall, UK.

their location relative to another layer (ESRI, 2016), in this case the habitat layer (lowland heathland). With the cookiecutter tool, one layer (habitat type) can be used to clip another layer (the sacred sites), to identify the sites that fall within a particular site of interest. Site selection was refined to ensure that sites had similar climatic and physical environments.

\section{Extent and spatial distribution of semi-natural sacred sites within lowland heathland}

Based on a literature search we identified 330 semi-natural sacred sites of 20 distinct types across Cornwall, with a high concentration in the Penwith region. The initial spatial analysis indicated that sites overlapped with various habitat types included in the Biodiversity Action Plan. The habitat with the greatest number of semi-natural sacred sites was lowland heathland. An Ordnance Survey map was used to identify which of the sites were also on open access land, and 40 such sites were identified. Sites that were on land owned either by Cornwall Council or the National Trust were selected. Of these, 16 semi-natural sacred sites within lowland heathland in Penwith had similar climatic and physical environments, and were therefore included in the study (along with 16 paired non-sacred sites). The shortest distance between two semi-natural sacred sites was $52 \mathrm{~m}$ and the longest distance was $2,610 \mathrm{~m}$. Ten sites lay within isolated patches of heathland, and the mean distance between the sites was $608 \mathrm{~m}$. The mean distance between sites in a single large patch of heathland was $356 \mathrm{~m}$.

\section{Fieldwork}

Fieldwork was conducted in June 2009 to investigate the structure and composition of the habitat, and to conduct species diversity and habitat heterogeneity surveys. The National Trust gave permission to work on openly accessible semi-natural sacred sites located on their land. Additionally, the Cornwall Historic Environment Department, National Heritage, Cornish Ancient Sites and the Cornish Interfaith Forum were informed about the work. To facilitate assessment of the importance of the presence of the stone monuments, each sacred site had a paired non-sacred site in the same area, which contained no structure or monument. Prior to the fieldwork a map was drafted, showing the locations of all the chosen stone monuments. The non-sacred sites had to be within the heathland area surrounding the sacred sites, but at a minimum distance of $50 \mathrm{~m}$ from the stone monuments (to ensure that the vegetation in sacred sites was not influenced by the vegetation in non-sacred sites and vice versa; S. Harris, 2009, pers. comm.). A grid was then laid on top of the map, the squares surrounding each site were numbered, and squares were chosen for the paired sites using a random-number generator. It was not possible to determine with certainty that the sites considered to be non-sacred had never had any sacred connotations, as monuments may have been destroyed or overgrown by the heathland (Media, 2009), but there was no current knowledge of any sacred association.

The length and width of each site was measured, and three line transects were surveyed at each site. The methods used for sampling vegetation followed Kent \& Coker (1992), Krebs (1999) and Sutherland (2006). A line intercept method was used to record species, cover and change. For areas of short grassland, in which the line intercept method was not feasible, a $50-\mathrm{cm}$ quadrat was used.

\section{Line transects}

For semi-natural sacred sites each transect started from the centre of the site and extended outwards to a distance that was $20 \%$ beyond the width of the site. The directions north, north-east, east, south-east, south, south-west, west and north-west were numbered $1-8$, respectively. The three transect lines to be surveyed were selected using a randomnumber generator. At one of the sites (Tregeseal tumuli) it was not possible to work from the centre outwards, and therefore transects started from the end point on the outside of the site and extended inwards to the centre. In each nonsacred site the same transect length was used as that used in the paired sacred site. Again, the direction of the transect was chosen at random and the line intercept method used to record species, frequency and cover (Krebs, 1999; Sutherland, 2006). We recorded the plant species that intersected the line, where they intersected the line and how 
TABLE 1 Sacred monuments in Penwith, Cornwall, UK (numbered sites in Fig. 1), assessed for their benefits to biodiversity in lowland heathland, Penwith, Cornwall, UK.

\begin{tabular}{lll}
\hline & Monument & \\
\cline { 2 - 3 } Site number & Name & Type \\
\hline 1 & Tregesseal Stone Circle & Stone circle \\
2 & Unknown & Holed stones \\
3 & Unknown & Tumuli \\
4 & Unknown & Standing stone \\
5 & Lanyon Quoit & Quoit \\
6 & Men An Tol & Stone circle \\
7 & Nine Maidens of Boskendnan & Stone circle \\
8 & Mulfra Quoit & Quoit \\
9 & Mulfra Tumuli & Tumuli \\
10 & Rosehill Cairn & Cairn \\
11 & Zennor Quoit & Quoit \\
12 & Nine Maidens Long Stone & Standing stone \\
13 & Nine Maidens Tumuli & Tumuli \\
14 & Watch Croft Standing Stone & Standing stone \\
15 & Watch Croft Cairn & Cairn \\
16 & Nine Maidens Ring Cairn & Cairn \\
\hline
\end{tabular}

much of the line was occupied by each species. Bare ground, patches of mosses/lichens and types of stone (including the central structures) were also recorded.

Samples of each plant species were taken in accordance with the Code of Conduct for the Conservation of Wild Plants (CABS, 1989). All species were assigned a number and placed in a plant press for subsequent identification by Dr Stephen Harris, Curator of Oxford University Herbaria. Plants were identified to species if possible, or otherwise to genus. If identification was not possible, the plant was assigned a letter. The mean vegetation height was calculated for each transect line. Three points were chosen at random along the line and measurements of height taken. A stick with a moveable disc was used to gauge the height, which was taken to be the length of the stick from the base to the point where the disc rested on the vegetation.

\section{Quadrats}

For areas of short grass that extended for $1 \mathrm{~m}$ or longer, a frame quadrat was used to record the species present and their relative frequencies. A $50-\mathrm{cm}$ fixed frame was subdivided into $2510 \times 10 \mathrm{~cm}$ squares and placed randomly in the patch of grass. The length of the patch was measured in centimetres, and then a distance was selected along the length using a random-number generator. The centre of the quadrat was placed at this distance. The presence of each plant in each square was recorded, and each plant was given a number, tagged and pressed for subsequent identification (Kent \& Coker, 1992; Krebs, 1999; Sutherland, 2006).

\section{Species Habitat Analysis}

Using an internet-based survey, a list of species identified as occurring in lowland heathland was compiled, along with the key habitat requirements for each species. The key habitat features required by the species were then compared to habitat features observed during the surveys of the sacred natural sites. The comparison was used to discover whether the sacred sites contained any of the identified habitat features required by the species.

\section{Data analysis}

We used a combination of methods to analyse the data. The statistical procedures used were based on Kent \& Coker (1992), Krebs (1999) and Sutherland (2006). The distribution of sacred sites within the heathland was analysed by measuring the distance between the sites, using the Ruler tool in $\operatorname{Arc}$ GIS v. 9. The mean distance between sites was calculated. Line transects and quadrats were analysed separately, as the two methods could not be combined for statistical analysis (Krebs, 1999; Sutherland, 2006). Grass was considered to be a single species in the line transects, which introduced an error in the analysis but was taken into account when interpreting the results. For the line transects, to compare species richness of vegetation and community heterogeneity between sacred and non-sacred sites we used a $\chi^{2}$ test, and the Simpson and ShannonWeiner diversity indices; to examine evenness of vegetation we used Simpson's measure of evenness. For the $\chi^{2}$ test, expected frequencies for both sacred and non-sacred sites were considered to be equal (half of total frequencies) and the P-value was taken from a $\chi^{2}$ probability table (Jones, 1999). To compare similarity between paired sacred and non-sacred sites, Jaccard's similarity index and percentage similarity measure were used (all indices used are summarized in Table 2).

To examine if plant diversity and similarity between sacred and non-sacred sites were significantly different we used a Mann-Whitney U test in SPSS $v .16$ (IBM, Armonk, USA). We used a $\chi^{2}$ test to analyse height differences between sacred and non-sacred sites, and to compare the height of vegetation within the main area of a site, referred to here as 'inner vegetation', and vegetation in the area that was in the ' $20 \%$ extended area' outside the site, referred to here as 'outer vegetation', within sacred sites, calculating the P-value using an online statistical calculator (Soper, 2009). Mean heights of vegetation in sacred and non-sacred sites were analysed using an independent $t$-test and Levene's test for equal variance, in SPSS. The formulas for the indices were taken from Krebs (1999).

For the quadrats, we used the number of species to analyse relative species richness (Krebs, 1999; Sutherland, 2006). To examine if the difference in species richness of 
TABLE 2 Indices used to analyse data collected in line transect surveys to assess differences in plant species and habitats between sacred and non-sacred sites in lowland heathland, in Cornwall, UK (Fig. 1; Table 1).

\begin{tabular}{|c|c|c|}
\hline Index & Formula & Definition \\
\hline Simpson's diversity index & $1-D=1-\sum\left(p_{i}\right)^{2}$ & $\begin{array}{l}D=\text { Simpson's index, } p_{i}=\text { proportion of species } i \text { in the } \\
\text { community }\end{array}$ \\
\hline Shannon-Wiener diversity index & $H^{\prime}=-\sum_{i}^{s}\left(p_{i}\right)\left(\log _{2} p_{i}\right)$ & $\begin{array}{l}S=\text { number of species, } p_{i}=\text { proportion of species in } i^{\text {th }} \\
\text { species }\end{array}$ \\
\hline Simpson's measure of evenness & $E_{1 / D}=1 / D_{\max }$ Where $D_{\max }=\sum p_{i}^{2} / S$ & $\begin{array}{l}p_{i}=\text { proportion of species } i \text { in the community } \\
S=\text { number of species in the sample }\end{array}$ \\
\hline Jaccard's similarity index & $S_{\mathrm{j}}=a /(a+b+c)$ & $\begin{array}{l}a=\text { number of species present in both types of site, } \\
b=\text { number of species present in non-sacred sites but } \\
\text { not present in sacred sites, } c=\text { number of species present } \\
\text { in sacred sites but not present in non-sacred sites }\end{array}$ \\
\hline Percentage similarity index & $P=\sum_{i} \operatorname{minimum}\left(p_{1 i}, p_{2 i}\right)$ & $\begin{array}{l}P=\text { percentage of similarity between samples } 1 \text { and } 2 \\
P_{1 i}=\text { percentage of species } \mathrm{i} \text { in community sample } 1 \\
P_{2 i}=\text { percentage of species } \mathrm{i} \text { in community sample } 2\end{array}$ \\
\hline
\end{tabular}

grass patches across sacred sites was significant, we used a $\chi^{2}$ test, calculating the P-value using an online calculator (Soper, 2009). Jaccard's similarity index was used to measure similarity (Krebs, 1999). Species abundance at each site was calculated using frequency methods as described by Sutherland (2006). The number of squares in the quadrat in which species occurred was calculated as a percentage of the total number of squares.

\section{Results}

Results from line transect surveys indicate a higher number of species, greater species diversity and a higher diversity of vegetation height in sacred vs non-sacred sites (Table 3 ). There was greater diversity in both community structure and composition within sacred sites compared to the surrounding heathland, which held fewer species and was dominated by Ulex gallii. In comparison, sacred sites were more diverse and had no dominant species.

Quadrat surveys were conducted in sacred sites 1, 4, 5, 6 and 11, as they contained extensive areas of grass along the transects. Although there was no statistical difference in the number of species, there was little similarity in the type of species across sacred sites (Table 4); i.e. sacred sites were similar in their level of species richness but differed in the types of species they contained. The greatest similarity was between sites 1 and 4, with a 0.4 similarity index (the similarity index ranges over $0-1$ ), and the least similarity was between sites 1 and 5, with a similarity of o.1.

The habitat features recorded in and around sacred sites included grassy patches, open areas, and a greater number of flowering and herbaceous species within a specified area compared to non-sacred sites, bare ground, mixed-height vegetation, rocks, sheltered areas, ditches, tracks and disturbed sites. A number of heathland species require habitat features provided by the existence, maintenance and use of sacred sites (Supplementary Table 1). Although some heathland species are negatively affected by disturbance (and therefore activity around sacred sites is likely to lead to a reduction in their presence), overall, our results show that the existence and use of sacred sites has resulted in greater biodiversity at these sites than is evident in the surrounding heathland.

Sacred sites had a higher level of habitat diversity than the surrounding heathland (Table 3). This is because of their greater species diversity, greater variation in vegetation height, and the existence of various habitat features that occur rarely (if at all) within the surrounding heathland (Table 3).

Anthropogenic activities that contribute to the maintenance of heathland include trampling, cutting back and disturbance of vegetation. There are also varied habitat patches in the landscape that are vital to a range of heathland species. Sacred sites have species and habitats that do not occur in other areas, and are areas of high biodiversity within a relatively low-diversity landscape.

\section{Discussion}

Anthropogenic influence promotes habitat and species diversity

Lowland heathland in the UK is important to biodiversity, both at a national and international scale (Price, 2003). We found various types of vegetation within the landscape. Semi-natural sacred sites had significantly greater species richness and heterogeneity, and contained different species compared to surrounding heathland. The heathland is species poor and comprises predominantly heather and gorse. There were no significantly dominant species in the sacred sites, and these sites are more diverse than non-sacred sites. Grass was considered to be a single species in the line 
TABLE 3 Factors investigated (in bold) in line transect surveys of sacred and non-sacred sites in lowland heathland in Cornwall, UK (Fig. 1; Table 1), with the tests used, results, and a summary of the findings.

\begin{tabular}{|c|c|c|}
\hline Test used & Result & Summary of finding \\
\hline \multicolumn{3}{|c|}{ Difference in number of plant species between sacred \& non-sacred sites } \\
\hline $\begin{array}{l}\text { Total number of species across } \\
\text { all sites }\end{array}$ & $\begin{array}{l}\text { Sacred sites: } 45 \text { species; non-sacred } \\
\text { sites: } 21 \text { species }\end{array}$ & $\begin{array}{l}\text { More plant species occurred within the sacred sites com- } \\
\text { pared to the non-sacred sites. }\end{array}$ \\
\hline$\chi^{2}$ & $\mathrm{P}<0.05^{*}$ & $\begin{array}{l}\text { Significantly more species occurred in the sacred sites than } \\
\text { in the non-sacred sites. }\end{array}$ \\
\hline \multicolumn{3}{|c|}{ Difference in occurrence of plant species } \\
\hline $\begin{array}{l}\text { Species with the highest level of } \\
\text { occurrence }\end{array}$ & $\begin{array}{l}\text { Sacred sites: Erica tetralix; non-sacred } \\
\text { sites: Ulex gallii }\end{array}$ & $\begin{array}{l}\text { The species with the highest occurrence was different in } \\
\text { sacred \& non-sacred sites. }\end{array}$ \\
\hline $\begin{array}{l}\text { Species with the highest coverage } \\
\text { (\% of total length of all transects) }\end{array}$ & $\begin{array}{l}\text { Sacred sites: Pteridium aquilinum; } \\
\text { non-sacred sites: Ulex gallii }\end{array}$ & $\begin{array}{l}\text { The species with the highest coverage was different in sacred } \\
\& \text { non-sacred sites. }\end{array}$ \\
\hline \multicolumn{3}{|c|}{ Level of similarity of plant species between sacred \& non-sacred sites } \\
\hline Jaccard's similarity index & $S_{\mathrm{j}}=0.375$ & $\begin{array}{l}\text { There was little similarity in the species found in the sacred } \\
\text { sites compared to those found in the non-sacred sites. }\end{array}$ \\
\hline Percentage similarity index & $44.78 \%$ & $\begin{array}{l}\text { There was little similarity in the species found in the sacred } \\
\text { sites compared to those found in the non-sacred sites. }\end{array}$ \\
\hline \multicolumn{3}{|c|}{ Difference in diversity of plant species between sacred \& non-sacred sites (based on Shannon-Weiner diversity index) } \\
\hline Mann-Whitney U test & $\mathrm{P}=0.000^{*}$ & $\begin{array}{l}\text { There was a significantly greater level of species diversity in } \\
\text { the sacred sites compared to the non-sacred sites. }\end{array}$ \\
\hline \multicolumn{3}{|c|}{ Level of heterogeneity of plant species within sites } \\
\hline Simpsons diversity index & $\begin{array}{l}\text { Sacred sites: } 1-D=0.946 \\
\text { non-sacred sites: } 1-D=0.806\end{array}$ & Sacred sites were more heterogeneous than non-sacred sites. \\
\hline Shannon-Wiener diversity index & $\begin{array}{l}H=3.10 \text { bits per individual in sacred } \\
\text { sites; } H=2.76 \text { bits per individual in } \\
\text { non-sacred sites }\end{array}$ & Sacred sites were more heterogeneous than non-sacred sites. \\
\hline Simpson's measure of evenness & $\begin{array}{l}\text { Sacred sites: } E_{1 / D}=0.41 \\
\text { non-sacred sites: } E_{1 / D}=0.24\end{array}$ & Sacred sites were more even than non-sacred sites. \\
\hline \multicolumn{3}{|l|}{ Variation in vegetation height } \\
\hline $\begin{array}{l}\text { Levene's test for equality of } \\
\text { variance }\end{array}$ & $f=20.244 \mathrm{P}=0.000^{*}$ & $\begin{array}{l}\text { Variation in height of vegetation in sacred sites was signifi- } \\
\text { cantly different to that in non-sacred sites, with sacred sites } \\
\text { having a significantly greater level of variance in vegetation } \\
\text { height than non-sacred sites. }\end{array}$ \\
\hline $\begin{array}{l}\text { Independent } t \text {-test (where equal } \\
\text { variance was not assumed) }\end{array}$ & $\mathrm{P}=0.000^{*}$ & $\begin{array}{l}\text { Significant difference in variation in height of vegetation } \\
\text { between sacred \& non-sacred sites, with sacred sites having a } \\
\text { significantly greater level of variance in vegetation height } \\
\text { than non-sacred sites. }\end{array}$ \\
\hline Standard deviation & $\begin{array}{l}\text { Sacred sites: } \mathrm{SD}=33.76 \\
\text { non-sacred sites: } \mathrm{SD}=19.86\end{array}$ & $\begin{array}{l}\text { Sacred sites had greater variation in the height of vegetation } \\
\text { than non-sacred sites. }\end{array}$ \\
\hline
\end{tabular}

${ }^{*}$ Indicates statistical significance

transect surveys, thus potentially understating the significance of the measures of species richness.

These differences between sacred sites and the surrounding heathland are probably attributable to a combination of both environmental conditions and anthropogenic activities. For example, which heath species are present depends on the level of soil moisture: Erica tetralix (wet heath) is more common at sacred sites whereas Erica cinerea (dry heath) is more common at non-sacred sites (D. Allen, 2009, pers. comm.; ES-W, 2012, pers. obs.). Some species are reliant on the presence of others. The obligate parasite Cuscuta sp. was found only on U. gallii, and thus the greater occurrence of $U$. gallii in non-sacred sites explains the higher frequencies of Cuscuta sp. in these sites compared to sacred sites (D. Allen, 2009, pers. comm.; ES-W, 2012, pers. obs.).

Differences in the community composition of sacred sites compared to the surrounding heathland may also be attributable to anthropogenic use of the sites, both past and present. Prehistoric land-use may have influenced the ecology and biodiversity of today's cultural landscapes (Willis et al., 2004; Bhagwat et al., 2008; Dudley et al., 2010). The contemporary use and maintenance of these sites and their structures are also likely to have a significant influence on the vegetation that occurs within them. It is evident from archaeological records that changes in land 
TABLE 4 Results of $\chi^{2}$ tests, and Jaccard's similarity indices examining the difference in plant species number and similarity in types of species found in sacred sites, based on data obtained from quadrat surveys in the sacred sites in lowland heathland, in Cornwall, UK (Fig. 1; Table 1). The results were corrected using the Bonferroni correction $(\mathrm{P} /$ number of comparisons: $0.05 / 10=0.005)$.

\begin{tabular}{llll} 
Sites compared & $\chi^{2}$ & $\mathrm{P}$ & Jaccard's similarity index \\
\hline 1 \& 4 & 0.286 & 0.593 & 0.4 \\
1 \& 5 & 2.88 & 0.0881 & 0.1 \\
1 \& 6 & 0.98 & 0.322 & 0.136 \\
1 \& 11 & 0.286 & 0.593 & 0.217 \\
4 \& 5 & 1.44 & 0.23 & 0.29 \\
4 \& 6 & 0.21 & 0.64 & 0.11 \\
4 \& 11 & 0 & & 0.263 \\
5 \& 6 & 0.57 & 0.45 & 0.36 \\
5 \& 11 & 1.441 & 0.23 & 0.286 \\
6 \& 11 & 0.214 & 0.643 & 0.235 \\
\hline
\end{tabular}

use and vegetation may have preceded the installation of stone structures in Cornwall (Howard, 1997; Yates, 2007). The stones themselves were often transported from a distance, and their installation introduced in the landscape a place of worship where Neolithic cultures performed rituals, including those related to the annual farming cycle. The provision of a novel feature in the landscape, with alternative land-use practices, could have led to the observed differences in biodiversity compared to other areas within the landscape, as has been reported for sacred sites elsewhere (Bhagwat \& Rutte, 2006; Dudley et al., 2010).

Sacred sites are exposed to various anthropogenic activities, including tourism, aesthetic appreciation, historic interest, outdoor pursuits, maintenance, and spiritual engagement. These activities affect the structure and composition of the surrounding areas. To provide access to the sites, plants have been removed or trampled to create paths. Parts of the heathland have been cut back, both to facilitate access and to ensure that the heather does not overgrow or damage the sites. In some areas grass has been planted around the monuments to provide support and keep the stones in place. At some sacred sites we found evidence of recent burning activities (associated with ritual practices). The use and maintenance of sacred sites has resulted in areas of trampled and disturbed vegetation; a reduction in the height of vegetation (through removal or cutting of plants); changes in habitat structure (presence of grassy patches, bare ground, and shady areas); and changes in the composition of species (dispersal of plants via human activity and movement, and the planting of new species). The use of sacred sites has also resulted in the sites being more structurally diverse than the surrounding heathland.

We observed people walking in and around sacred sites, as well as signs of dogs, birds, rabbits and livestock. The movement of people and animals between sites is likely to facilitate dispersal of seeds and small animals such as insects. This may result in the introduction of new plant and animal species, thus contributing to the higher levels of biodiversity within sacred sites. In comparison, nonsacred sites often contained dense vegetation, limiting access and consequently dispersal of species. Some of the sacred sites include burial grounds, which will have altered the nutrients within the soil, at least in the past, and consequently influenced the plant communities at those sites.

Although there are differences in how sacred sites are used now compared to formerly, there are also many similarities (especially in relation to worship and spiritual practices). Historically the sites may have been visited by fewer people, but they are likely to have been visited regularly, and at times by large groups of people for specific rituals and ceremonies (Burl, 2000; A2M, 2009). Therefore it is probable that the original use of the sites would have resulted in similar disturbance activities to those that take place now (including cutting back of the heather and creation of pathways), as well as creating similar habitat features (such as bare ground), leading to similar impacts on biodiversity within the landscape.

\section{Presence of unique habitats and species}

For effective conservation it is important to know not only which species are present but also their relative abundance and the characteristics of the community. The heterogeneity of vegetation and vegetation structure at sacred sites promotes greater plant biodiversity, providing a variety of food and habitat types and promoting greater faunal diversity (Price, 2003; Whittaker \& Fernandez-Palacios, 2007).

The presence of the monuments as well as the management and uses of the sacred sites affect plant community structure. Management techniques such as cutting back, as well as trampling and grazing by animals and the use of sites by people affect both the species present and the community structure within and surrounding the sites. At the edges of the sacred sites there is an increase in vegetation height where the maintained areas cease and the surrounding heathland begins. This further increases the habitat diversity within the heathland matrix and is likely to promote biodiversity within the landscape. A number of features within sacred sites are seldom present in the surrounding heathland, including stones and bare ground. These provide alternative habitats, and features such as bare soil, basking areas and increased shade, which help to promote species such as the wood tiger beetle Cicindela sylvatica, the adder Vipera berus and the nightjar Caprimulgus europaeus (Kirby, 1992; Key, 2000; Price, 2003; D. Allen, 2009, pers. comm.).

\section{Heathland management}

The main approaches to heathland management in Cornwall include the removal of trees, the use of grazing animals, and 
systematic burning (English Nature, 2002). Some grazing animals, including cattle, prefer younger heather and grassland, and therefore this approach is ineffective for managing mature heathland. This is the case especially in areas with sacred sites, where there are usually patches of grass and young heather and the cattle graze on these rather than on the mature heather. Cattle have also caused damage to standing stones by scratching against them (Shepheard-Walwyn, 2012, pers. comm.). During the study we talked to people we met whilst conducting fieldwork (these were informal conversations with individuals who happened to be visiting the sites at the time that fieldwork was conducted). These conversations revealed that many members of the general public believed that people interested in the conservation of the heathland were disrespectful of those who use the heathland for recreational or spiritual purposes, and they thought that conservationists wanted to limit public use of the sites. Although many of those involved in heathland conservation dispute these perceptions, there is a potential conflict between conservationists and some users of the sites.

A number of the recreational users who were met at the sites had noticed a decrease in the biodiversity of the heathland following changes to access and management practices in some areas. In particular a decrease in bird sightings was noted following the cessation of manual cutting of heather and the introduction of cattle, and a decrease in sightings of both birds and herptiles was noted following the limitation of access to areas of the heathland that are now dominated by mature heather. Manually maintaining the heathland is time consuming and labour intensive. Organizations such as the Wildlife Trust and Natural England often depend on volunteers to undertake such management activities (Natural England, 2016; CWT, 2016). At present English Heritage is responsible for the maintenance of a number of sacred sites in the Penwith region, and other sites are managed voluntarily by independent groups. English Heritage has $>2,000$ volunteers, who conduct $>400,000$ educational site visits each year (English Heritage, 2016). At present the conservation organizations have little interaction with the organizations and groups interested in maintaining and preserving the heritage of sacred sites. This is a missed opportunity for conservationists, in terms of engagement and access to volunteer resources. If conservation groups could engage those that use the sites for their spiritual and cultural heritage values, they would be able to reach a wider audience and could potentially manage the heathland and its biodiversity more effectively, whilst also preserving the sacred sites.

\section{Timing of fieldwork and interpretation of data}

The findings of the fieldwork were sent to Cornwall Wildlife Trust. The plant data were added to the local species databases, and the land-use maps have been of value to the Trust as prior to this 2009 study the most recent publicly available national maps with information on habitat status and species' ranges in Cornwall were from the 2005 Biodiversity Action Plan. The survey results reported here remain the most up-to-date field data for the surveyed sites. The Biodiversity Action Plan information and the associated maps are currently being updated, and our data will help inform these updates.

Lowland heathland is still a Biodiversity Action Plan priority habitat in the UK, vital to rare and endemic species, and cultural and sacred sites are of significant importance to biodiversity conservation. The methodologies for managing lowland heathland in the study region remain the same as they were at the time of the fieldwork, and comparison of aerial imagery from 2016 with photographs and field notes from 2009 indicates there have been no apparent significant changes at the sites.

\section{Limitations of the study}

Our findings indicate that semi-natural sacred sites are important for heathland biodiversity, but the research was limited in scope. To understand fully the impact of the presence of sacred sites on biodiversity within lowland heathland a greater number of sites would need to be assessed across Cornwall and other areas of the UK. This study is a snapshot in time, and not a full analysis of the ecological communities present at the sites. To examine in greater detail the importance of semi-natural sacred sites to both biodiversity and habitat heterogeneity within the heathlands would require study at various times throughout the year and over a number of years. We focused on plant diversity; further research is needed to include other organisms.

\section{Conclusions}

We found that the presence of semi-natural sacred sites within lowland heathland increased both biodiversity and habitat heterogeneity, highlighting the importance of interactions between various types of cultural sites for biodiversity conservation. The existence, use and maintenance of sacred sites in the landscape gives rise to habitat features that are important for a range of species and may not be present in other areas of the heathland. These sites exist only because of their use and management as sacred places, and therefore when managing landscapes for biodiversity conservation, the use and management of these sacred places should not only be acknowledged but should be integral to the overall management approach. Combining the resources, interests and activities of those conserving the heathland and those conserving the standing stones would facilitate more effective and sustainable management. Our findings highlight the need for a more holistic 
understanding of the types of cultural landscapes that exist in an area, and the importance of managing such landscapes in a culturally sensitive manner. By acknowledging the alternative values of natural and semi-natural environments, and working with those that use the landscape for cultural and spiritual practices, conservation practitioners can find new ways of increasing biodiversity, and gain additional support for conservation management.

\section{Acknowledgements}

We thank Cornwall Wildlife Trust for their help in providing mapping layers, as well as advice and guidance on the project; The National Trust for allowing access to sites on their land; and Dr Stephen Harris (Curator of Oxford University Herbaria), for his work on plant identification, which was invaluable to this project.

\section{Author contributions}

ESW designed the project, conducted the data collection and analysis, and wrote the article. SAB advised on the project design, supervised the work and contributed significant input to, and critical editing of, the article.

\section{References}

A 2 M (2009) Cornwall's archaeological heritage: A field guide to accessible sites. Access to monuments. Http://www.historiccornwall.org.uk/a2m/index.htm [accessed 20 August 2009].

Agnoletti, M. (2004) Cultural landscapes and biodiversity: a case study suggesting a different approach in conservation strategies in Italy. In Monitoring and Indicators of Forest Biodiversity in Europe From Ideas to Operationality (ed. M. Marchetti), pp. 287-298. EFI Proceedings No. 51. European Forest Institute, Joensuu, Finland.

Anthwal, A., Gupta, N., Sharma, A., Anthwal, S. \& Kim, K.H. (2010) Conserving biodiversity through traditional beliefs in sacred groves in Uttarakhand Himalaya, India. Resources, Conservation and Recycling, 54, 962-971.

ARC Trust (2016) Https://www.arc-trust.org/ [accessed 5 April 2016]. Arkive (2016) Http://www.arkive.org/species/ [accessed 4 April 2016].

Bhagwat, S.A. \& Rutte, C. (2006) Sacred Groves: potential for biodiversity management. Frontiers in Ecology and the Environment, 4, 519-524.

BhagWat, S.A., Willis, K.J., BirKs, H.J.B. \& WhitTAKER, R.J. (2008) Agroforestry: a refuge for tropical biodiversity? Trends in Ecology \& Evolution, 23, 261-267.

BurL, A. (2000) The Stone Circles of Britain, Ireland and Brittany. Yale University Press, London, UK.

Burnham, A. (2001) The megalith map. Http://www.megalithic.co.uk/ asb_mapsquare.php [accessed 2 June 2009].

Butterfly Conservation (2016) Butterflies and moths. Http:// butterfly-conservation.org/44/butterflies-and-moths.html [accessed 5 April 2016].

CABS (Conservation Association of Botanical Societies) (1989) Code of Conduct for the Conservation and Enjoyment of Wild Plants. Conservation Association of Botanical Societies, London, UK.
CWT (Cornwall Wildlife Trust) (2016) Volunteer. Http://www. cornwallwildlifetrust.org.uk/volunteer [accessed 7 April 2016].

Devon County Council (2016) The Devon Biodiversity Action Plan. Https://new.devon.gov.uk/environment/wildlife/ the-devon-biodiversity-action-plan-bap [accessed 6 April 2016].

Dudley, N., Bhagwat, S., Higgins-Zogib, L., Lassen, B., Verschunren, B. \& Wild, R. (2010) Conservation of biodiversity in sacred natural sites in Asia and Africa: a review of the scientific literature. In Sacred Natural Sites: Conserving Nature and Culture (eds B. Verschuuren, R. Wild, J.A. McNeely \& G. Oviedo), pp. 19-32. Earthscan Ltd., London, UK.

English Heritage (2016) English Heritage: facts and figures. Http:// www.english-heritage.org.uk/about-us/search-news/press-releases/ facts-and-figures/ [accessed 6 April 2016].

English Nature (2002) Lowland Heathland - A Cultural and Endangered Landscape. English Nature, Peterborough, UK.

Forestry Comission (2017) Lowland heath. Http://www.forestry. gov.uk/forestry/lowlandheath [accessed November 2017]

Gaillard, M.-J., Dutoit, T., Hjelle, K., Koff, T. \& O’Connell, M. (2009) European cultural landscapes: insights into origins and development. In Cultural Landscapes of Europe (eds K. Krzywinski, M. O’Connell \& H. Kuster), pp. 35-44. Aschenbeck Media, Bremen, Germany.

Hantsweb (2009) Biodiversity. Http://www3.hants.gov.uk/ biodiversity/environment-biodiversity-landmanagement/ heathland/heathland-biodiversity-2.htm [accessed 20 August 2009].

Heil, G.W. \& Aerts, R. (1993) General introduction. In Heathlands: Patterns and Processes in a Changing Environment (eds R. Aerts and G.W. Heil), pp. 1-24. Springer Science and Business Media, Dordrecht, The Netherlands.

Historic Environment Service (2009) Historic Cornwall. Http:// www.historic-cornwall.org.uk/ [accessed 20 August 2009].

Howard, A. (1997) West Penwith. Cornwall Wildlife Trust, Truro, UK.

JNCC (Joint Nature Conservation Committee) (2009) The UK Biodiversity Action Plan. Http://jncc.defra.gov.uk/page-5155 [accessed 15 June 2009].

JONES, J. (1999) Table: Chi-Square Probabilities. Http://people.richland. edu/james/lecture/m17o/tbl-chi.html [accessed 11 August 2009].

Jones, M. (2003) The concept of cultural landscape: discourse and narratives. In Landscape Interfaces: Cultural Heritage in Changing Landscapes (eds H. Palang \& G. Fry), pp. 21-52. Kluwer, Boston, USA.

Kent, M. \& Coker, P. (1992) Vegetation Description and Analysis: A Practical Approach. Belhaven Press, London, UK.

KEY, R.S. (2000) Bare ground and the conservation of invertebrates. Brisitsh Wildlife, 11, 183-191.

Kirby, P. (1992) Habitat Management for Invertebrates: A Practical Handbook. RSPB, Sandy, UK.

Krebs, C. (1999) Ecological Methodology. Addison Wesley Longman, New York, USA.

Media, J. (2009) Cornish Ancient Sites Protection Network. Http:// www.cornishancientsites.com [accessed 18 August 2009]

Moran, E.F. (2006) People and Nature: An Introduction to Human Ecological Relations. Blackwell Publishing, Oxford, UK.

Natural England (2008) West Penwith ESA. Http://webarchive. nationalarchives.gov.uk/20140605103224/http://www. naturalengland.org.uk/ourwork/farming/funding/closedschemes/ esa/westpenwith.aspx [accessed 23 January 2018].

Natural England (2016) Volunteering with Natural England. Http://www.gov.uk/guidance/volunteering-with-natural-englandhow-to-get-involved [accessed 15 July 2016].

Oldfield, T.E.E., Smith, R.J., Harrop, S.R., \& Leader-Williams, N. (2004) A gap analysis of terrestrial protected areas in England 
and its implications for conservation policy. Biological Conservation, 120, 303-309.

Pembrokeshire County Council (2016) Species Action Plans. Https://www.pembrokeshire.gov.uk/biodiversity/ pembrokeshire-nature-partnership-plans-and-guidance [accessed 11 October 2017].

PRATt, E. (2015) 'It's all magical and made up really': negotiating between academic and alternative narratives of British prehistory. Archaeological Review from Cambridge, 30, 56-70.

Price, E. (2003) Lowland Grassland and Heathland Habitats. Routledge, London, UK.

Robinson, R.A. (2017) BirdFacts: profiles of birds occurring in Britain \& Ireland. Http://www.bto.org/birdfacts [accessed 23 January 2017].

RSPB (The Royal Society for the Protection of Birds) (2016) Bird Guide. Http://www.rspb.org.uk/birds-and-wildlife/ bird-and-wildlife-guides/bird-guide/ [accessed 5 April 2016].

ShepheARD-Walwyn, E. (2014) Culture and conservation in the sacred sites of Coastal Kenya. $\mathrm{PhD}$ thesis. University of Kent, Canterbury, UK.

Soper, D. (2009) P-value calculator for a chi-square test. Http://www. danielsoper.com/statcalc/calculator.aspx?id=11 [accessed 11 October 2017].

Sutherland, W.J. (ed.) (2006) Ecological Census Techniques: A Handbook. Cambridge University Press, Cambridge, UK.

TAYLOR, B.R. \& KAPLAN, J. (eds) (2008) The Encyclopedia of Religion and Nature: Volume 1. Continuum, London, UK.

UNESCO (2016) Http://whc.unesco.org [accessed 29 June 2016].
Whittaker, R.J. \& Fernandez-Palacios, J.M. (2007) Island Biogeography: Ecology, Evolution and Conservation. Oxford University Press, Oxford, UK.

Willis, K.J., Gillson, L. \& BRNCIC, T.M. (2004) How "virgin" is virgin rainforest? Science, 304, 402-403.

XiAnG, W.N. (1993) Application of a GIS-based stream buffer generation model to environmental policy evaluation. Environmental Management, 17, 817-827.

Y Ates, D.T. (2007) Land, Power and Prestige: Bronze Age Field Systems in Southern England. Oxbow Books, Oxford, UK.

\section{Biographical sketches}

Emma Shepheard-WALwyn has a background in natural and social sciences and her research has focused on biodiversity conservation, development, culture and spirituality. She is currently working as the acting Environmental and Social Governance Director for a forestry company in East Africa, and continues to conduct interdisciplinary research into environmental conservation in developing countries. SHONIL A. BHAGWAT is an interdisciplinary scholar with a background in natural and social sciences. His research interests focus on the links between environment and development, addressing the perceived environmental challenges within the context of increasing discussion on the Anthropocene, the age of humans. In particular, his work on sacred natural sites has focused on the role of these sites in the conservation of biocultural diversity, one of the contemporary global challenges. 